\title{
Re-entry high altitude pulmonary edema in the Himalayas
}

A 7 year old Nepali boy of Tibetan ancestry fell ill when he ascended to his village (Manang, 3500m) from Besi-Sahar $(760 \mathrm{~m})$ in one day in a motor vehicle. He together with his family had spent the winter (December to March) at low altitude at Besisahar. In Manang he complained of difficulty in breathing and intermittent cough after the journey, but his parents ascribed this to the rough ride on a bumpy road. The boy's dyspnea increased over night and during the following day, prompting his parents to take him to the local village health post where he was diagnosed with influenza-like illness and was managed symptomatically with simple cough medicines. His symptoms worsened again over night. The next morning (day three since ascending to Manang village) his parents sought help at the Himalaya Rescue Association (HRA) aid post in Manang, which is primarily tasked with the prevention and treatment of altitude related illnesses in the region. In addition to the breathlessness he now had a severe headache and had vomited twice over night. He had no significant past medical history. The parents said that last year they had come up the same road with a similar ascent profile with no untoward events. In years past, prior to the construction of the road, they said they would trek up to Manang from Besi-Sahar which would take several days.

On presenting to the HRA aid post, the patient was observed to be minimally responsive with globally reduced tone. Work of breathing was markedly increased with a respiratory rate of 55 breaths per minute, chest wall retraction, use of accessory muscles and nasal flare. Oxygen saturation measured by portable saturation probe was $44 \%$. Chest auscultation revealed good air entry, which was equal bilaterally, but with crepitations throughout the lung fields. Heart 
rate was 150 beats per minute and temperature was $35.7 \mathrm{C}$. He was diagnosed with re-entry high altitude pulmonary edema(HAPE)(Scoggin et al., 1977, Hultgren et al., 1978) and high altitude cerebral edema (HACE)(Basnyat et al., 2003) and was treated with high-flow oxygen, and $3 \mathrm{mg}$ of dexamethasone. A helicopter rescue was organized to fly him to Kathmandu (1300m).

In Kathmandu, the treating doctor found him to have improved markedly. He was oriented appropriately, his vital signs were within normal limits and he was ambulating with a normal gait. His oxygen saturation was $94 \%$ in room air with bilateral crepitations. His blood count, routine urine, creatinine, and liver function tests were normal. The chest X-ray revealed heterogeneous opacities in the lower and mid zones bilaterally (Figure 1). He was discharged to his hotel in Kathmandu with no medicines and followed up after two days. In his follow up consultation he was noted to have normal vesicular breath sounds with no added sounds and his repeat chest $X$ ray was normal (Figure 2 ). He continued to do well and we last followed up a month ago.

High altitude pulmonary edema ( HAPE) is a medical emergency due to a non-cardiogenic form of edema with elevated pulmonary artery pressures often seen in trekkers, mountaineers, and pilgrims who ascend ( usually $>3000 \mathrm{~m}$ ) too high too fast(Basnyat et al., 2003). The pathophysiological mechanism of HAPE is primarily thought to be mechanical with patchy smooth muscle constriction of the pulmonary vasculature triggered by hypobaric hypoxia(Basnyat et al., 2003). Unlike, in the case of pneumonia where opacities or consolidation may remain for weeks on the chest $\mathrm{X}$ ray, the prompt disappearance of the 
patchy opacities in our patient's chest $\mathrm{X}$ ray within days is in keeping with HAPE(Zafren et al., 2009).

Re-entry high altitude pulmonary edema, which is a subset of HAPE is a well -recognized, lifethreatening illness documented so far almost exclusively in the North and South Americas when people, who live at high altitude ( $>2500 \mathrm{~m}$ ), return to their homes after a brief sojourn of days to months at a lower altitude setting(Scoggin et al., 1977, Hultgren et al. 1978, Niermeyer et al. 2009).

Re-entry HAPE as described in our patient has not been reported in Sherpas or other people of Tibetan origin in Nepal or India. There has been only one report from Tibet(Wu, 2004). Children seem to be more susceptible to re-entry HAPE than adults(Hultgren et al., 1978). A few explanations have been put forward to explain the lack of re-ascent HAPE in the Himalayan highlanders. Severinghaus (Sevringhaus, 1971) postulated that chronic hypoxia of high altitude causes increased muscularization of the pulmonary arterioles. This generates excessive pulmonary arteriole pressure on re ascent to high altitude to which children may seem more predisposed to. Due to poorer adaptation to high altitude by the Andean native in comparison to the Tibetan- origin highlanders(Moore, 2001), this phenomenon may be more commonly seen in the South Americans. Another explanation suggests that re ascent HAPE may be due to change in blood volume because prolonged exposure to high altitude results in increased blood volume(Wu, 2004). When the high altitude resident descends to lower altitude there is decrease in red cell mass resulting in compensatory rise in plasma volume which may predispose to pulmonary edema on return to high altitudes. 
We suggest that another explanation for the rarity of this illness in Himalayas relative to that in South America ( for example, Peru where this phenomenon is well described(Hultgren et al., 1978 ) is that historically a lack of roads in the high altitude Himalayas has largely prevented rapid re-ascent for high altitude residents sojourning after a temporary stay at lower altitudes. Lack of such roads may have previously protected children from re-entrant HAPE since rapid reascent is known to be an important risk factor in this disease. Now road building in the region, including the road recently completed from Besi-Sahar to Manang, along which this patient traveled, may contribute to an increased prevalence of re-entrant HAPE (Reisman, In press).

In addition, health workers at high altitudes in Nepal where re-entrant HAPE is unknown may select an alternate diagnosis as clearly happened in our patient. This may easily lead to a fatal outcome, as may have happened in this case had it not been for the prompt diagnosis and treatment by the Himalaya Rescue Association aid post doctors. Proper awareness regarding reentry HAPE in Himalayan high altitude natives needs to be created in high altitude population in this region including in high altitude health workers. In this way, proper diagnosis and treatment with oxygen and rest or, if necessary, descent can be carried out promptly for effective treatment of re-entry HAPE.

\section{References}

Basnyat B, Murdoch DR(2003). High-altitude illness. Lancet 361(9373): 1967-1974.

Hultgren HN, Marticorena EA(1978). High altitude pulmonary edema. Epidemiologic observations in Peru. Chest 74(4): 372-376. 
Moore LG(2001). Human genetic adaptation to high altitude. High Alt Med Biol 2(2): 257-279.

Niermeyer S, Andrade Mollinedo P, Huicho L(2009). Child health and living at high altitude. Arch Dis Child 94(10): 806-811.

Reisman J, Deonarain D, Basnyat B. Impact of a Newly Constructed Motor Vehicle Road on Altitude Illness in the Nepal Himalayas. Wilderness Environ Med ( in press).

Scoggin CH, Hyers TM, Reeves JT, Grover RF(1977). High-altitude pulmonary edema in the children and young adults of Leadville, Colorado. N Engl J Med 297(23): 1269-1272.

Sevringhaus J(1971). Transarterial leakage: A possible mechanism of high altitude pulmonary edema.

High Altitude Physiology: Cardiac and Respiratory Aspects. J. K. R Porter. London, England, Churchill Livingstone.

Wu T(2004). A Tibetan with chronic mountain sickness followed by high altitude pulmonary edema on reentry. High Alt Med Biol 5(2): 190-194.

Zafren K, Basnyat B and Basnyat G(2009). Clinical images: a pneumonic confusion. Wilderness Environ Med 20(1): 81-82. 